\title{
Measuring the Risk of Impulsive Noise at Work: One Practitioner's Tips
}

\author{
Elizabeth Brueck ${ }^{1}$
}

Received: 20 October 2015 / Accepted: 28 January 2016 / Published online: 9 February 2016

(C) The Author(s) 2016. This article is published with open access at Springerlink.com

\begin{abstract}
There is a risk of immediate damage to hearing from short duration, high-level impulsive sounds that are typically perceived as "bangs". These sounds may arise from impact action tools, weaponry, and explosive events. The risk is normally associated with the instantaneous peak sound pressure level. Reliable measurement of these high-peak sound pressure levels can be challenging, particularly when special low-sensitivity microphones or transducers are required. It is also important that the health and safety practitioner is aware of the limitations of their instrumentation and the limitations of various types of measurement and analysis when sound is impulsive. Included here are tips from the author's practical experience of testing the performance of noise measurement instrumentation and hearing protection in impulsive noise, and notes of standard methods to estimate the attenuation provided by hearing protection.
\end{abstract}

Keywords Noise $\cdot$ Peak $\cdot$ Hearing protection $\cdot$ Impulsive $\cdot$ Measuring

\section{Assessing Exposure from Impulsive Noise}

Excessive noise exposure is known to cause hearing loss that is in addition to the normal loss due to aging. The loss is gradual, increasing as excessive exposures are repeated. The level, duration, and frequency of repeated exposures are risk factors. Hearing damage can also be caused immediately by sudden, extremely loud noises. These noises are typically perceived as "bangs" and may arise from heavy impactive tools, weaponry, and explosive events. This risk is normally determined by the instantaneous peak sound pressure level at the ear. This risk is in addition to the contribution of the sound to the overall A-weighted noise exposure.

In Great Britain, regulation of noise exposure at work comes under the Control of Noise at Work Regulations [1]. These regulations are the implementation of the EU Physical Agents (Noise) Directive [2] and they define the actions employers are required to take to control noise exposures in

Elizabeth Brueck

elizabeth.brueck@hsl.gsi.gov.uk

1 Health and Safety Laboratory, Harpur Hill, Buxton SK17 9JN, UK the workplace. The regulations set action and limit values for personal noise exposure. The peak noise limit value is $140 \mathrm{~dB}$ measured as the instantaneous $\mathrm{C}$-weighted peak sound pressure level or $L_{\mathrm{C} \text {,peak }}$. (This same limit value is applicable in most Australian jurisdictions [3]). In Great Britain, action to control exposure is required when personal exposure is likely to exceed a lower exposure action value of $135 \mathrm{~dB}(\mathrm{C})$. These peak noise action and limit values are in addition to those for the A-weighted daily personal noise exposure $\left(L_{\mathrm{EP}, \mathrm{d}}\right)$, a value which is equivalent to the $L_{\text {Aeq, } 8 \mathrm{~h}}$. Detailed guidance supporting these regulations is provided by the Health and Safety Executive (HSE) in "Controlling noise at work" [4] and in a simpler, more concise guide "Noise at work-A brief guide to controlling the risks" [5].

The HSE guidance "Controlling noise at work" provides typical values for the levels of some processes that produce high-peak noise levels together with guidance on the selection of hearing protection. However, it also notes that specific measurement of the peak level is required for those sources not listed. When measurements are made the guidance states only that meters conforming to IEC 61672-1 Class 2 [6] or better, or IEC 804 Type 1 [7] will be suitable, and that they should be set to measure the $L_{\mathrm{C} \text {,peak }}$. But in extreme sound 


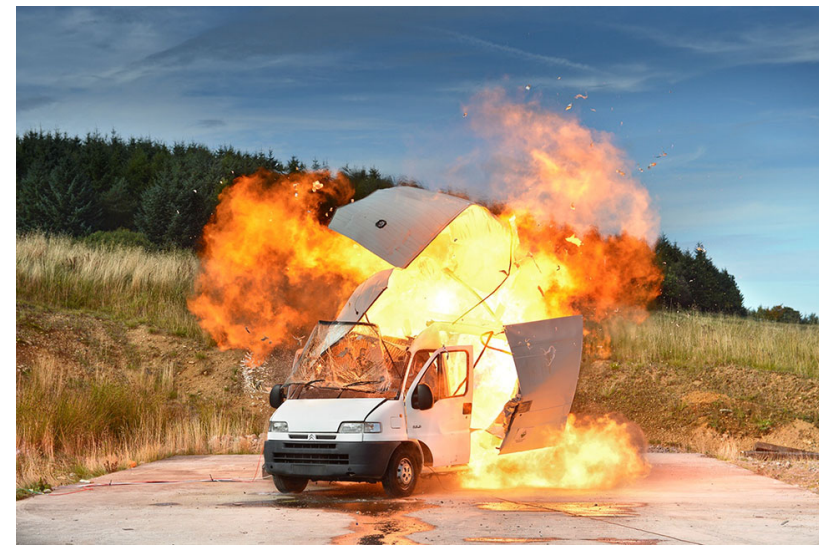

Fig. 1 Explosive event at the Health and Safety Laboratory (image provided by HSL Visual Presentation Services team)

levels Fig. 1, it is not so simple; specialist instrumentation may be required.

I have many years of experience making measurements of impulsive sound to assess the risk to hearing, and to determine personal exposure and hearing protection requirements. I have also been involved with development of sound level meter and hearing protector standards. What I have included here are tips for the health and safety practitioner based on my own practical experience, together with reference to other helpful sources.

\section{Where are the Risks?}

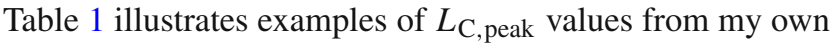
measurements of common sources of impulsive noise such as impact action tools and machinery, firearms, and explosive

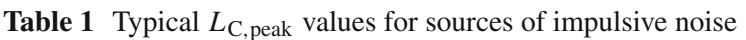

\begin{tabular}{|c|c|}
\hline$L_{\mathrm{C} \text {,peak }} \mathrm{dB}$ & Source \\
\hline$<140$ & $\begin{array}{l}\text { Hand hammers in wood working and hot metal } \\
\text { fabrication } \\
\text { Proof firing of shot gun cartridges } \\
\text { High velocity rifle with efficient moderator }\end{array}$ \\
\hline $140-150$ & $\begin{array}{l}\text { Proof firing of high velocity ammunition } \\
\text { Hand held powered impactive tools } \\
\text { High pressure water jetting } \\
\text { Pneumatic hammers } \\
\text { Fireworks } \\
\text { Small caliber hand guns }\end{array}$ \\
\hline $150-160$ & $\begin{array}{l}\text { Shot gun } \\
\text { Large caliber hand guns }\end{array}$ \\
\hline $160+$ & $\begin{array}{l}\text { Hunting rifle } \\
\text { Military weaponry } \\
\text { Stun grenades }\end{array}$ \\
\hline
\end{tabular}

devices. These values are the exposure of the operator, or the exposure at the noisiest location a person might be. If noise controls are applied exposures may be reduced.

\section{Determining Exposure Without Measurement}

Measurement of high-peak sound pressures can require specialist instrumentation, and so it makes sense to look for reliable information that is already available. European legislation requires the manufacturer or supplier of machinery to report the $L_{\mathrm{C} \text {,peak }}$ at the operator's position if this exceeds $130 \mathrm{~dB}$, and the $L_{\text {Aeq }}$ if this exceeds $70 \mathrm{~dB}$ [8]. Thus information may already be in the public domain. When using a manufacturer's or other published data, it is also necessary to check that the data provided are applicable to your own use and operation of the machine or device.

If a risk is suspected, but simple, inexpensive controls are available to reduce the risk, it makes sense to apply these controls and so possibly eliminate the risk and the need for measurements with specialist instrumentation.

\section{Measurement Instrumentation for High-Peak Sound Pressures}

\subsection{The Right Sound Level Meter or Measurement System}

The international standard for sound level meters is IEC 61672-1 [6]. In Great Britain, a sound level meter or measurement system used for assessing noise exposure should meet either this or the Type 1 requirements of the now superseded standards IEC 804 [7] and IEC 651 [9]. If your meter conforms to these older standards only, I recommend you check with the manufacturer if your meter is likely to be compliant with the peak indication requirements in IEC 61672-1. This precaution is important as the specification for the peak indication in these older standards is limited. In Great Britain, a sound level meter used for assessing noise exposure should also be submitted at least every two years for a periodic standard verification test. (This is a short test, against the main standard requirements, given in IEC 61672-3 [10] for verification of instruments manufactured to IEC 61672-1.) Often the manufacturer will be able to provide access to this service.

I recommend avoiding instruments that are not compliant with any standards because while they may calibrate and indicate correctly in steady sound I find errors are typically over $15 \mathrm{~dB}$ when measuring impulsive sound. I have also encountered instruments that are specified as meeting sound level meter standards, but in fact are not compliant.

Before buying a sound level meter, it is prudent to ask the manufacturer if the instrument model, or a similar model in the range, has passed pattern evaluation in accordance 
with IEC 61672-2 [11] (this is a detailed test against the full requirements of the standard normally carried out at a national test laboratory). If this is not the case for a model of sound level meter you already own, I would recommend taking it through a standard verification test to check for any obvious noncompliance if you have not done this before.

Sound level meters are graded as Class 1 or Class 2 (Type 1 and 2 in the older standards). Close to the source, sounds can be dominated by high frequencies, creating more of a "crack" than a "bang." Here a Class 1 or Type 1 instrument is best as it has a tighter specification at higher frequencies. If you use a device that has a variable sample rate ensure, this is sufficient to capture frequencies up to $20 \mathrm{kHz}$.

\subsection{Low-Sensitivity Microphones}

Most sound level meters are designed to measure sound pressure levels within our normal environment. With the associated microphone, they typically overload on the least sensitive range around an unweighted sound pressure level of $140 \mathrm{~dB}$. The capability to measure higher sound pressure levels can usually be achieved using a microphone that has lower sensitivity and a range that extends to higher sound pressure levels. Typically the use of a 1/4 inch microphone in place of a 1/2-inch microphone will allow measurements to around $160-170 \mathrm{~dB}$.

\subsection{Alternative Transducers for Extreme Sound Levels}

Peak levels over $170 \mathrm{~dB}$ occur from stun grenades, military weaponry, and large explosions. At these extreme sound pressure levels, your choice of microphone is limited and can be expensive. There are alternative devices that can take the place of a microphone at these extreme sound levels.

Some acoustic equipment manufacturers have recommended to me using hydrophones for the measurement of high-sound pressure levels in air. I have not tried these but I have successfully validated and used dual purpose constant current line drive (CCLD) microphone/pressure sensors. These had been originally purchased to measure blast pressures.

If you use alternative transducers I recommend making additional checks to confirm the performance with your measurement equipment. As a minimum, I would check the transducer sensitivity when used with the meter or measurement system corresponds to the value given in the latest calibration. If you can do additional tests, I recommend making laboratory checks of the frequency response and spot checks of level linearity. To confirm the response at high-peak sound pressures, I would make simultaneous, comparative measurements in impulsive sound with the transducer and with a microphone as a reference. I would measure $L_{\mathrm{C} \text {, peak }}, L_{\mathrm{A} \text {, peak }}, L_{\mathrm{CF} \text {, max }}$ and $L_{\mathrm{AF} \text {, max }}$ and pro- vided the sounds are well within the measurement range of each device, and I would expect differences of no more than $1.5 \mathrm{~dB}$ between the measurements with the transducer and reference microphone.

\subsection{Other Practical Issues}

- Do note that low-sensitivity microphones and transducers will have a higher noise floor and may, as a result, give a falsely high indication of lower level sounds.

- Your microphone/ transducer may overload below the level that will trigger the meter or measurement system overload indication. If this is the case, you will not see overload indications. I always note the upper limit of my microphones and transducers and check the peak indications are well within the measurement range. If possible, I would also advise monitoring the wave-form of the impulse event.

- High frequencies can exist, particularly close to the source. The $\mathrm{A}$ and $\mathrm{C}$ frequency weightings are only defined up to $20 \mathrm{kHz}$. You may need an additional low pass filter to remove frequencies above the audible frequency range. The microphone/ transducer will also disturb the high-frequency sound field. To minimize this disturbance orientate, a free field device to face the direction of sound, and a pressure response device perpendicular to the direction of the sound.

- I recommend the use of a sound calibrator that provides a suitable sound pressure level for the field checks of sensitivity. A device providing a nominal level of $114 \mathrm{~dB}$ at $1 \mathrm{kHz}$ or a pistonphone providing a level of $124 \mathrm{~dB}$ at $250 \mathrm{~Hz}$ is a better choice than a calibrator providing a tone at $94 \mathrm{~dB}$. The calibrator sound level will only be specified for certain microphones. The calibrator sound level may not be specified for the microphone/ transducer you are using. If this is the case, set your instrumentation to the microphone/ transducer sensitivity given with its latest calibration. Use the sound calibrator to check for consistency of indication when working in the field.

- Low-sensitivity devices can have a comparatively high sensitivity to vibration. I recommend providing vibration isolation for the microphone mounts and supports when working indoors or in enclosed spaces where structure borne vibration may occur.

\section{What Should You Measure?}

\subsection{Estimating Personal Noise Exposure}

If you are assessing personal noise exposure measure the $L_{\mathrm{C} \text {,peak }}$ over one or more impulse events. The peak level exposure is indicated by the highest level event. 
There is also a risk associated with the daily personal noise exposure or $L_{\text {Aeq, } 8 \mathrm{~h}}$. In impulsive sound this is related to the level and number of impulsive events the person is exposed to in the day. I recommend calculating this from a measurement of the sound exposure level $\left(L_{\mathrm{AE}}\right)$ which is the noise exposure normalized to $1 \mathrm{~s}$. This is a measurement usually available on an integrating sound level meter or measurement system. It is useful for measurement of discrete short duration events because the indication is proportional to the number of events in the measurement, and not the measurement duration. Simply

$L_{\mathrm{Aeq}, 8 \mathrm{~h}}=L_{\mathrm{AE}}-44.6+10 \log (N / n) \mathrm{dB}$

where $N$ is the number of events the person is exposed to in a day, $n$ is the number of events in the $L_{\mathrm{AE}}$ measurement, 44.6 is the conversion factor in $\mathrm{dB}$ between an exposure normalized to $1 \mathrm{~s}$ and an exposure normalized to $8 \mathrm{hs}$.

\subsection{Estimating Frequency Content}

In impulsive sound it is generally not possible to obtain a reliable measurement of the frequency spectrum associated with the peak level of the impulsive event. Also artificial transients, (filter ringing) not contained in the sound but associated with filter responses to an impulse, may contaminate the measurement. A measurement of the difference in the $\mathrm{C}$ and A-weighted sound levels ( $L_{\mathrm{C}}$ minus $L_{\mathrm{A}}$ value) of the event is an alternative indication of the frequency content. A negative $L_{\mathrm{C}}$ minus $L_{\mathrm{A}}$ value indicates high frequencies dominate while increasing positive values indicate increasing dominance of low frequencies.

\subsection{Selecting Hearing Protection}

The passive attenuation of a hearing protector (the attenuation without any electronic amplification or active noise cancelation) is obtained by measuring the change in the threshold of hearing of a group of human subjects with and without the protector worn. This passive attenuation data is provided with all protectors. Only the passive attenuation is effective in high-level impulsive sound.

Some protectors are designed to provide increased passive attenuation in high-level impulsive sound. If these devices are used you will need advice from the manufacturer or supplier on the expected protector attenuation. The advice given in the following paragraphs is not applicable to these devices.

I have used two standard methods for estimating passive protector attenuation in impulsive noise. One is included in the European standard EN 458 [12] and a second method is included in a new revision of a UK defence standard; DEF STAN 00-27 revision I3 [13] .

\subsubsection{EN 458 Method}

EN 458 lists common sources of impulsive noise and places them into three frequency types. The type for any impulsive sound is simply determined by comparison with the example sources listed. The protector attenuation for each type is a modified sound attenuation value obtained from the $H$, $\mathrm{M}$ and $\mathrm{L}$ values provided with the manufacturer's passive attenuation data (as defined in ISO 4869-2 [14]).

- Type 1 low-frequency sources are assigned the $\mathrm{L}$ value minus $5 \mathrm{~dB}$.

- Type 2 medium to high-frequency sources are assigned the $M$ value minus $5 \mathrm{~dB}$.

- Type 3 high frequency sources are assigned the $\mathrm{H}$ value.

The modified sound attenuation value is applied to the $L_{\mathrm{C} \text {,peak }}$ and the $L_{\mathrm{AE}}$ of the sound. This method is reproduced in the HSE guidance "Controlling noise at work" [4]. However the HSE guidance states that for military and industrial impulsive noise sources for which there is no source information provided, measurements are required.

\subsubsection{DEF STAN 00-27 Method}

This standard extends the EN 458 method to use measurement of the frequency character of the sound. The method calculates an $L_{\mathrm{C}}$ minus $L_{\mathrm{A}}$ value from the difference in the measured maximum $\mathrm{C}$ and $\mathrm{A}$-weighted sound pressure levels of the impulse event using a F (Fast) time constant; i.e., $L_{\mathrm{CF} \text {, max }}$ minus $L_{\mathrm{AF} \text {, max }} \mathrm{dB}$. The standard provides five frequency categories with boundaries defined by $L_{\mathrm{C}}$ minus $L_{\mathrm{A}}$ values. For each category a modified sound attenuation value is assigned using the passive attenuation $\mathrm{H}, \mathrm{M}$ and $\mathrm{L}$ values provided by the manufacturer. The details of the category boundaries and the modified sound attenuation values are shown in Table 2. The method is applicable to sounds with an $L_{\mathrm{C}}$ minus $L_{\mathrm{A}}$ up to $+10 \mathrm{~dB}$. For low-frequency sounds with a higher $L_{\mathrm{C}}$ minus $L_{\mathrm{A}}$ value extension of the method is unreliable.

Table 2 Modified hearing protection sound attenuation values for impulse or impact noises from DEF STAN 00-27

\begin{tabular}{ll}
\hline $\begin{array}{l}L_{\mathrm{CF}, \max } \\
\text { minus } \\
L_{\mathrm{AF}, \max } \mathrm{dB}\end{array}$ & $\begin{array}{l}\text { Modified sound } \\
\text { attenuation } \\
\text { value dB }\end{array}$ \\
\hline$<0$ & $\mathrm{H}$ \\
$>0-1$ & $\mathrm{M}$ \\
$>1-3$ & $\mathrm{M}-5$ \\
$>3-5$ & $\mathrm{~L}$ \\
$>5-10$ & $\mathrm{~L}-5$
\end{tabular}




\section{Conclusion}

Much of what I have included here are personal hints and tips. Research and standardization are in progress. Keep an eye on the literature for future developments.

Acknowledgments This publication was funded by the Health and Safety Executive (HSE). Its contents, including any opinions and/or conclusions expressed, are those of the author alone and do not necessarily reflect HSE policy.

Open Access This article is distributed under the terms of the Creative Commons Attribution 4.0 International License (http://creativecomm ons.org/licenses/by/4.0/), which permits unrestricted use, distribution, and reproduction in any medium, provided you give appropriate credit to the original author(s) and the source, provide a link to the Creative Commons license, and indicate if changes were made.

\section{References}

1. UK Statutory Instrument: The control of noise at work regulations 2005 (S.I. 2005/1643), HM Government (2005)

2. European Parliament, Council: Directive 2003/10/EC of the European Parliament and of the Council of 6 February 2003 on the minimum health and safety requirements regarding the exposure of workers to the risks arising from physical agents (noise), OJ EU L42 pp. 38-44 15 Feb 2003

3. Australian Government: Health and Safety Commission, National standard for occupational noise [NOHSC: 1007(2000)] 2nd Edition (2000)

4. HSE, Controlling noise at work, The Control of Noise at Work Regulations 2005, Guidance on Regulations (L108), HSE Books
5. HSE Noise at work - A brief guide to controlling the risks INDG362(rev2) HSE Books 2012

6. International Electrotechnical Commission, IEC 61672-1:2013 Electroacoustics. Sound level meters. Specifications

7. International Electrotechnical Commission, IEC 804:1981 Integrating-averaging sound level meters

8. European Parliament, Council, DIRECTIVE 2006/42/EC OF THE EUROPEAN PARLIAMENT AND OF THE COUNCIL of 17 May 2006 on machinery, and amending Directive 95/16/EC (recast)., OJ L 157, p. 24, 9 June 2006

9. International Electrotechnical Commission, IEC 651:1979 Sound level meters

10. International Electrotechnical Commission, IEC 61672-3:2013 electroacoustics. Sound level meters. Periodic tests

11. International Electrotechnical Commission, IEC 61672-2:2013 electroacoustics. Sound level meters. Pattern evaluation tests

12. European Standard: EN 458:2004 Hearing protectors. Recommendations for selection, use, care and maintenance. Guidance document , European Committee for Standardization (2004)

13. MODUK - British Defence Standards (MODUK), DEF STAN 0027 Revision I3 The measurement of impulse noise from military weapons, explosives and pyrotechnics; and selection of hearing protection, MODUK-British Defence Standards (MODUK) (2015)

14. International Standard: ISO 4869-2:1995 Acoustics. Hearing protectors. Estimation of effective A-weighted sound pressure levels when hearing protectors are worn, International Organization for Standardization (1995) 